\title{
ENTRE A CANTORIA E A SALA DE AULA: REFLEXÕES SOBRE $O$ PAPEL DA MÚSICA EM NOVAS MATRIZES CURRICULARES DE ESCOLAS TIMBIRA
}

ALEXANDRE HERBETTA ${ }^{1}$

$U F G$

\begin{abstract}
RESUMO: Este texto trata de analisar o papel da música em algumas experiências de reformulação de matrizes curriculares em escolas indígenas do Brasil central, especialmente em populações timbira, como os Krahô, Apinajé, Gavião e Krikati. Estas matrizes curriculares têm como eixo a elaboração de novas práticas pedagógicas, as quais tomam como base a musicalidade de cada população. Estas experiências se dão em diálogo com o Núcleo Takinahaky de Formação Superior Indígena da Universidade Federal de Goiás. Deste modo, busca-se refletir, em primeiro lugar, acerca do potencial musical nos processos de ensino e aprendizagem das escolas em tela, evidenciando-se concepções interessantes sobre música, cultura e pedagogia. Em seguida, busca-se questionar o modelo de matriz curricular típico da educação escolar brasileira contemporânea, que diminui o valor da educação musical para a formação das pessoas e tem como base valores eurocêntricos. Propõe-se, por fim, políticas públicas de educação escolar indígena voltadas aos regimes de conhecimento ameríndios, nos quais a musicalidade tem papel preponderante. Desta forma, aventa-se a possibilidade de se contribuir para a descolonização das escolas indígenas brasileiras.
\end{abstract}

PALAVRAS-CHAVE: educação; música; escola; indígena; descolonização.

ABSTRACT: This paper aims to analyze the role of music in some experiences of curriculum reformulation in indigenous schools of Central Brazil, especially in Timbira populations, such as the Krahô, Apinajé, Gavião and Krikati peoples. These curriculum matrices are based on the development of new teaching practices, which take their basis from the musicality of each population. These experiences occur in dialogue with the Takinahaky Center for Indigenous Higher Education, in Federal University of Goias. Thus, we try to think, first, about the musical potential to the processes of teaching and learning in these schools, which points out to interesting ideas about music, culture and pedagogy. Then we seek to question the typical curriculum model of contemporary Brazilian school education, which reduces the value of music education and basis itself on eurocentric values. It is proposed ultimately that public policy to indigenous education must be based on Amerindian knowledge systems, in which the musicality has a predominant role. Thus, this paper points out to the possibility of contributing to the decolonization of Brazilian indigenous schools.

KEYWORDS: education; music; school; indigenous; decolonization.

\footnotetext{
${ }^{1}$ Professor no Núcleo Takinahaky de Formação Superior Indígena e no Programa de Pós-Graduação em Antropologia Social da Universidade Federal de Goiás. E-mail: alexandre herbetta@yahoo.com.br .
} 
A música expressa a si mesma! Stravinsky (apud MORAES, 1983, p. 12).

A machadinha de pedra não é feita por homem. Ela foi encontrada e trazida pelo índio chamado de Hartãt, ele era muito sábio, conhecia muito bem a natureza como: árvores, animais, as aves e mais coisas. Conhecia também os cânticos de cada. Animais e aves Dodanin Piiken Krahô (2014).

A música também tem que mudar... tem que mudar... e a música também tem que mudar... Chico Science (2014, n.p.).

Este texto trata de processos de reformulação de matrizes curriculares em escolas indígenas que fazem parte do projeto do Núcleo Takinahaky de Formação Superior Indígena (NTFSI) da Universidade Federal de Goiás (UFG). Busca-se aqui, mais especificamente, analisar o papel da música nas novas matrizes curriculares em elaboração, especialmente em escolas timbira, como nos Krahô, nos Apinajé, nos Gavião e nos Krikati.

O estudo aqui apresentado toma como seus dados falas, práticas e documentos produzidos por acadêmicos e acadêmicas indígenas do referido núcleo, assim como documentos acerca da educação escolar brasileira. Procura-se igualmente fazer uma leitura da legislação que trata da educação musical de maneira geral e, ainda, refletir sobre a situação em relação à consolidação de uma educação escolar indígena diferenciada.

Neste sentido, a possibilidade de haver uma matriz curricular mais musical rompe com pressupostos etnocêntricos em relação às artes e, mais especificamente, à música. Deste modo, busca-se refletir em primeiro lugar acerca do potencial musical nos processos de ensino e aprendizagem das escolas em tela, evidenciando-se concepções interessantes sobre música, cultura e pedagogia. Em seguida, busca-se questionar o modelo de matriz curricular típico da educação escolar 
brasileira contemporânea, que diminui o valor da educação musical dentre outras coisas - para a formação das pessoas e tem como base valores eurocêntricos.

O NTFSI é um espaço de pesquisa e formação no campo da educação escolar indígena e da educação intercultural. Constitui também a possibilidade de acesso e permanência de indígenas no ensino superior. Existe há oito anos e é constituído por cursos de graduação e de pós-graduação no nível de especialização.

Atualmente, conta com cerca de 300 professores e professoras indígenas dos estados de Goiás, Mato Grosso, Tocantins e Maranhão, pertencentes à 20 distintas etnias, entre elas, os Krahô, Apinajé, Javaé, Karajá, Guarani, Xambioá, Canela, Gavião, Guajajara, Kuikuro, Krikati, Tapirapé, Xerente, Kamaiurá, Juruna, Timbira, Waurá, Xavante, Xacriabá e Tapuia. Estes professores e professoras buscam construir novas matrizes curriculares para que seus alunos possam compreender e produzir um novo mundo, com base nos princípios da interculturalidade, da decolonialidade, da transdisciplinaridade e da contextualização (MENDES ROCHA, PIMENTEL DA SILVA e BORGES, 2010).

Tais reflexões buscam, ainda, referendar a elaboração de novos projetos político-pedagógicos (PPPs) nas escolas indígenas em tela, os quais possuem novas dinâmicas de gestão educacional e inovadoras práticas pedagógicas. Isto, de modo a se rever a violência convencional do contato interétnico, marcada muitas vezes no processo de colonialidade do saber (LANDER, 2005, pp. 21-53) e implementada, entre outros mecanismos, através da escola.

Estas novas matrizes permitem, assim, a problematização de aspectos centrais dos modelos pedagógicos e sociais impostos de fora e presentes na educação indígena convencional, os quais são baseados em uma matriz epistêmica eurocêntrica de saber. Para Lander,

as categorias, conceitos e perspectivas [eurocêntricas] (economia, Estado, sociedade civil, mercado, classes, etc.) se convertem, assim, não apenas em categorias universais para a análise de qualquer realidade, mas também em proposições normativas que definem 0 dever ser para todos os povos do planeta. Estes conhecimentos convertem-se, nos padrões a partir dos 
quais se podem analisar e detectar as carências, os atrasos, os freios e impactos perversos que se dão como produto do primitivo ou o tradicional em todas as outras sociedades (LANDER, 2005, p. 27).

Assim, categorias que fundamentam outras epistemologias são inferiorizadas e deixadas de lado na escola convencional. A música (ou as artes) nesta escala passa a ser percebida como de menor valor frente a outras áreas do saber. Diante deste cenário, a educação musical passa a ter um valor hierárquico inferior a, por exemplo, ciências ou matemática na matriz curricular da escola convencional. Para Huhte (2014), professor krahô, entretanto, música é matemática - e vice-versa.

A música na escola indígena aponta então para o campo do que se pode chamar pedagogias decoloniais, no sentido de Walsh (2013, pp. 248), pois busca refundar outras possibilidades de entendimento e produção do mundo, problematizando e transformando categorias eurocêntricas convencionais. Para a autora, estas são

pedagogías que trazan caminos para críticamente leer el mundo e intervenir en la reinvención de la sociedad, como apuntó Freire, pero pedagogías que a la vez avivan el desorden absoluto de la descolonización aportando una nueva humanidad, como señaló Frantz Fanon (WALSH, 2013, p. 10).

Nesta direção, nas matrizes em análise, a música não é vista apenas como um recurso pedagógico, cujo objetivo é transmitir determinado conteúdo ou habilidade. Ou mesmo, não é vista apenas para o aprendizado de sua forma e estrutura musical, como se verá. Ela é entendida enquanto pedagogia - onde conteúdo e forma não podem ser dissociados. Trata-se, portanto, de pensar a música enquanto potencial de ensino e aprendizagem e de transformação.

Note-se, ainda, que mesmo nas escolas não indígenas a discussão sobre a importância de uma educação musical é bastante presente e importante.

Desvalorazição epistêmica: a música enquanto entretenimento? 
Para Chervel (1990), é importante o estudo dos mecanismos que recortam os conteúdos presentes nas matrizes curriculares da educação escolar de modo a se entender a sociedade em referência. Na mesma direção, Dantas (2015, p. 94) afirma que a construção do currículo não é algo neutro, mas "ao contrário, a seleção dos conteúdos e conhecimentos é reflexo de uma atitude política". A desvalorização da educação musical e o sumiço da música nas matrizes curriculares brasileiras apontam, portanto, para aspectos interessantes da política educacional e para o que se pensa acerca da formação de pessoas no país.

A educação musical no Brasil perdeu valor e espaço enquanto processo de ensino e aprendizagem especialmente na década de 1970, ao longo da ditadura militar. Neste cenário, a música passou a ser excluída constantemente do currículo escolar, dando lugar a outras disciplinas, mais diretamente a de educação artística - genericamente classificada, a partir da Lei 5.692/1971. Para Subtil (2012), no período, há um foco maior nas artes plásticas. Segundo a autora, se referindo a um estudo acerca da Revista Brasileira de Estudos Pedagógicos (RBEP) de 1973, pode-se dizer que há "ênfase às artes plásticas em detrimento das artes cênicas e da educação musical" (SUBTIL, 2012, p. 140).

Desta maneira, a música é duplamente desqualificada na matriz curricular. Uma por conta de ser percebida com menor importância do que outras disciplinas, como matemática e ciências, por exemplo, como mencionado. Outra por ser a menos praticada dentre as artes. A educação musical passa a ser posicionada, então, em espaço inferior na matriz curricular da educação escolar convencional. Neste contexto, segundo Fonterrada,

no mesmo período em que os países desenvolvidos adotavam, ao lado da performance (banda, coro orquestra) e das práticas de escuta, interessantes movimentos de criação musical e composição nas escolas, baseados na estética e nos procedimentos da música contemporânea, no Brasil perdia-se, nesse mesmo espaço, não apenas os procedimentos, mas a própria disciplina, escavando-se o vale que, desde então, abriu-se entre música e a escola (FONTERRADA, 2008, p. 341). 
A autora lembra ainda que realizou-se no Fórum Global de Salzburg em 2011 encontro que tratou do potencial musical para a educação (FONTERRADA, 2016, p. 1). Conforme a mesma, elaborou-se na ocasião um manifesto que apontava a música como elemento fundamental para a cidadania plena, fundamentando novas visões sobre a educação musical e propondo uma nova valoração da educação musical na matriz curricular da educação escolar.

Nesta direção, a educação musical tem sido vista cada vez mais, como

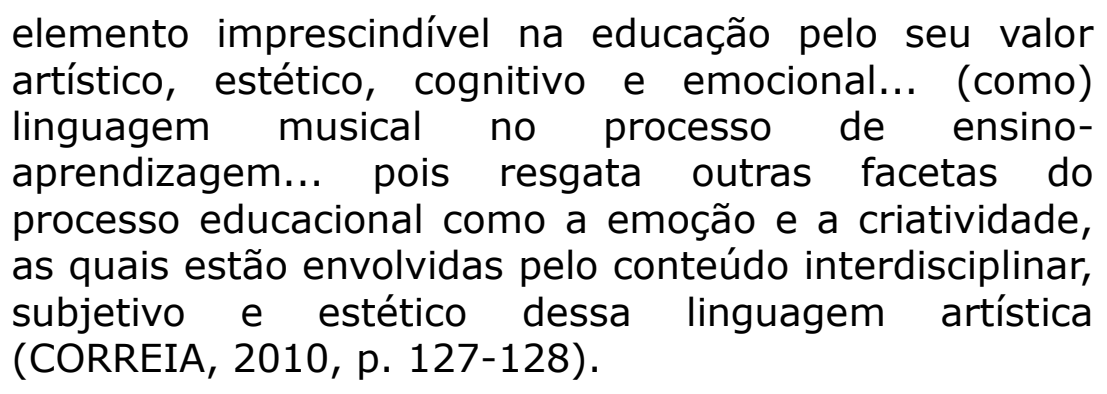

A Lei 11.769/2008, inclusive, passa a obrigar o ensino de música em todas as escolas do país - o que não ocorre na prática. Note-se que, dentre outras questões, a lei não determina claramente se a educação deve ser uma disciplina independente ou se deve estar integrada na educação artística.

Tal paradoxo - entre o potencial da música para a educação e o não uso da mesma nas escolas brasileiras - se dá por uma série de razões. Uma delas tem a ver com o fato de que a música, na contemporaneidade, acaba assumindo um valor relacionado ao domínio do lazer, e não tanto da formação humana. Para Fonterrada,

\begin{abstract}
se o valor da música é um consenso entre os músicos, não o é em outros segmentos da sociedade, sendo pertinente a discussão, em um âmbito mais amplo do que o espaço da arte, para que se perceba que a questão do acesso ao fazer artístico ultrapassa a do lazer ou da indústria de entretenimento (FONTERRADA, 2008, p. 11).
\end{abstract}

A legislação brasileira, inclusive, apoia esta nova perspectiva da educação musical. A Lei de Diretrizes e Bases da Educação Nacional (Lei 9.394/1996) estipula que a música constitui domínio do conhecimento 
e não apenas forma de lazer.

Na mesma direção, a música é considerada muitas vezes como domínio de especialistas. Figueiredo (2004) trata do assunto. Ele toma como base uma pesquisa realizada em universidades acerca da formação musical de professores generalistas. Segundo o autor, tais cursos partem do princípio de que a música e, consequentemente, a educação musical, é um campo para especialistas que possuem um dom especial. Para o mesmo autor,

\begin{abstract}
os professores generalistas não são matemáticos mas incluem matemática em sua prática cotidiana; não são cientistas mas abordam as ciências em suas atividades de ensino; não são poetas nem escritores mas são responsáveis por questões da língua portuguesa; mas normalmente não se sentem confiantes para aplicar questões artísticas e musicais por se considerarem desprovidos de talento para tal. Essa situação coloca a música e também as outras artes como pertencentes a um tipo exclusivo de conhecimento humano, acessível apenas para um número restrito de pessoas que nascem com os dons necessários para usufruir dessa condição (FIGUEIREDO, 2004, p. 56).
\end{abstract}

De acordo com o Conselho Nacional de Educação (CNE), entretanto, "a Lei não tem como objetivo formar músicos, mas desenvolver a criatividade, a sensibilidade e a integração dos alunos" (CRAVEIRO apud ALGAYER e TRUGILLO, 2013, p. 2).

Em seguida, pode-se notar que muitas vezes a educação musical é percebida de maneira reducionista e fragmentária. A discussão ocidental muitas vezes centra-se sobretudo no caráter sensual, integrador e criativo da música, deixando de lado seu potencial de formação intelectual-cognitivo dos sujeitos. Assim, muitas vezes a música é percebida apenas como recurso pedagógico para a transmissão de determinado conteúdo - uma espécie de potencializador da aprendizagem, por conta de seu caráter lúdico e emocional.

Em outras tantas ocasiões, ela é percebida apenas a partir de seu potencial de simbolização (RIZZON, 2009, p. 5; RENNER, 2009, p. 87), evidenciado especialmente na relação entre escuta, emoção e significado. Trata-se, sobretudo, de ênfase da perspectiva voltada à sonoridade. Para Menezes Bastos (2014, p. 3), entretanto, não é possível 
"reduzir a expressão da música (o som) - sua fonologia e gramática - a seu contexto (o comportamento) e vice-versa". Segundo o autor, reduzir a linguagem musical à sensorialidade pura, deslocando-a do domínio da inteligibilidade, "constitui um absurdo, lugar de nascimento das tautologias que dominam as elaborações sobre a questão do sentido musical feitas de dentro das Ciências Humanas e de suas satelizadas musicologias" (MENEZES BASTOS, 2014, p. 4).

O próprio fato de se pensar a música de maneira disciplinar é bastante contraditório, pois vai de encontro a uma de suas características principais, qual seja a de articular vários campos da cultura ou do conhecimento, como os domínios da escrita, da oralidade, da emoção, da criatividade e da cognição. Neste sentido, para Subtil (2012, p. 125-151), o processo de disciplinarização das artes tem como objetivo justamente o controle sobre tais formas de expressão e reflexão. Para a autora, inclusive, a Lei 5.692/1971 - já mencionada -, que cria a disciplina de educação artística na ditadura militar, tem como fim o controle sobre as possibilidades das artes na educação.

Neste sentido, para Wisnik (1989), a música pode articular o ético, o estético e o corporal, transcendendo barreiras dicotômicas, como entre a linguagem escrita e a oralidade, entre a razão e a emoção. Para o autor, "a música fala ao mesmo tempo ao horizonte da sociedade e ao vértice subjetivo de cada um, sem se deixar reduzir às outras linguagens" (WISNIK, 1989, p. 13). Para ele,

\begin{abstract}
a música não refere nem nomeia coisas visíveis, como a linguagem verbal faz, mas aponta com uma força toda sua para o não-verbalizável; atravessa certas redes defensivas que a consciência e a linguagem cristalizada opõem à sua ação e toca em pontos de ligação efetivos do mental e do corporal, do intelectual e do afetivo (WISNIK, 1989,p. 28).
\end{abstract}

A despeito dessas visões reducionistas, Campbell e Dickson (2000, apud CORREIA, 2010, p. 136) apontam que, além de promover sensações e operar com a criatividade, a música exerce papel fundamental na cognição. Os autores lembram que

na Hungria observa-se, no trabalho de Zoltan Kodály, que nas escolas as crianças cantam todos os dias. Já na 
Alexandre Herbetta - ENTRE A CANTORIA E A SALA DE AULA...

terceira série os alunos produzem sons belos $\mathrm{e}$ agradáveis. Nota-se que, os mesmos, vão muito bem em ciências e matemática, devendo-se a isso sua prática diária do canto. A percepção musical possui suas próprias normas e estruturas mentais de pensamento, nem sempre ligadas a outras formas de inteligência (CAMPBELL e DICKSON, 2000, apud CORREIA, 2010, p. 136).

Fonterrada corrobora a ideia. Para a autora, há muita discussão sobre o tema "sem sequer tocar na ideia de música como forma de conhecimento" (2008, p. 12-13). Nesta direção, para Correia,

a música pode e deve ser utilizada em vários momentos do processo de ensino-aprendizagem, sendo um instrumento imprescindível na busca do conhecimento, sendo organizado sempre de maneira lúdica, criativa, emotiva e cognitiva (CORREIA, 2010, p. 139).

É evidente, portanto, que a educação musical pode ter um papel mais destacado no sistema educacional nacional, qual seja o de se posicionar de maneira protagonista na matriz curricular da escola. Melhor dizendo, é interessante se pensar na possibilidade de termos matrizes curriculares mais musicais, revalorizando o papel da música como formadora das pessoas. Para Fonterrada, apenas assim a educação musical "poderá cumprir seu papel funcional de co-formadora do individuo e da sociedade, no restabelecimento de valores ético e estéticos" (FONTERRADA, 2008, p. 346-347).

Para a mesma autora,

até que cada indivíduo, em particular, e a sociedade, como um todo, se convençam de que ela é uma parte necessária e não periférica da cultura humana, até que se compreenda que seu valor é fundamental, ela terá dificuldades para um lugar proeminente e no sistema educacional (FONTERRADA, 2008, p. 349).

Pode-se dizer, então, que o desafio de se revalorizar a educação musical nas matrizes curriculares constitui uma atitude pedagógica decolonial, no sentido de Walsh (2013), pois problematiza e rompe com pressupostos fragmentários e reducionistas, típicos de uma epistemologia eurocentrada, a qual busca neutralizar as artes e, 
especialmente, o potencial musical e é, ainda, marca hegemônica do sistema educacional brasileiro, que constitui, como se pode aventar, projeto de formação acrítico e para o capital.

Note-se que este modelo de matriz curricular colonizada, no sentido aqui proposto, permeia e influencia o currículo de uma gama imensa de experiências pedagógicas realizadas em diferentes tipos de escola, inclusive na escola indígena.

\section{Estudos de caso: a música enquanto matriz de saberes}

No breve cenário exposto, algumas escolas timbira do Brasil central, as quais se relacionam ao projeto do NTFSI, tratam da educação musical de maneira especial e marcante. Elas apresentam propostas de uma educação musical inovadora e interessante. Seus professores e professoras criam e aplicam uma série de práticas pedagógicas, muitas vezes tendo como centro a música. Atualmente muitas destas escolas passam, inclusive, por um processo de reformulação de suas matrizes curriculares.

Note-se que os Timbira constituem-se por alguns povos que se percebem parentes no Norte e Nordeste brasileiros, como os Apinajé, Krahô, Gavião, Krikati e Canela. Eles possuem, portanto, universos culturais similares. Note-se, ainda, que um dos temas centrais do NTFSI é a reformulação das matrizes curriculares das escolas indígenas, o que se dá a partir das noções de decolonialidade, protagonismo indígena e transdicisplinaridade.

A música, em muitos destes casos, aparece enquanto o tema central da aula. Nestes casos o objetivo da prática pedagógica é o de transmitir determinado repertório musical. Como se verá, a ideia não se resume a dominar os cantos, mas abrange também a compreensão de aspectos centrais da criação e (re) produção dos mesmos. Outras tantas vezes, as práticas pedagógicas musicais buscam articular a música a outros aspectos culturais, como as histórias dos antigos, os cantos não indígenas, como o forró, a Festa da Batata, a complexa organização social e política, a nomeação, a exploração capitalista, dentre outros. A música parece, então, promover a compreensão das armações e 
relações entre domínios diversos.

Tal situação é observada igualmente por outros professores do NTFSI. Segundo Pechincha,

como sentem que não mais contam hoje com as condições ideais para assegurarem essa memória, vêem no registro escrito e audiovisual dos cantos e ritos um recurso à mão para garantir o seu conhecimento pelas gerações futuras e estão envidando esforços para a sua introdução nos currículos escolares. A atenção dirigida aos cantos krahô se faz, portanto, impulsinada pela necessária problematização da relação entre a ação da escola e práticas culturais krahô, com foco nas implicações da transposição das segundas para o âmbito dos currículos escolares, entendida como oportuna pelos professores krahô (PECHINCHA, no prelo, p. 2).

Como se pode ver, a música timbira parece ter um papel destacado nas referidas comunidades. Para Borges (2015), por exemplo,

o repertório das canções é praticamente infinito, já que os Krahô cantam sobre tudo o que existe no mundo... as letras das canções falam sobre detalhes dos distintos aspectos do real; elas são uma forma de linguagem que faz circular informações e conhecimentos acerca dos seres e das agências que povoam o cosmos (BORGES, 2015, p. 27).

Conforme Aldé, ainda "muitos dos cantos Krahô se dedicam à simples captura de uma imagem, um jeito de ser, aos movimentos e às cores, detalhando cada pedacinho do universo" (2013, p. 57). Na mesma direção, para Azanha,

as palavras da música Timbira cantam (descrevem) o mundo, ou melhor, todas as coisas belas e inusitadas dos seres que povoam esta terra e que são dignas de serem eternizadas na única maneira humana em que o seriam; a música (AZANHA, 2004, p. 2 apud BORGES, 2015, p. 27).

As reflexões acima expressas apresentam a música de maneira polissêmica e importante. Ela representa o belo e é ao mesmo tempo codificadora dos saberes. Indica percepções, estilos, tendências e 
condutas. Constitui mesmo uma linguagem que produz e circula conhecimento, estabelecendo redes sociais.

O universo krahô, como se percebe, é bastante musical, e os cantos marcam os momentos dos sujeitos tanto espacialmente, no território, quanto a partir das temporalidades, determinando períodos do dia e do calendário anual. Há músicas que devem ser cantadas em lugares específicos e em momentos particulares. Assim, há músicas do pátio, da caçada, da roça, assim como há músicas do amanhecer, do entardecer e da madrugada, do período seco e do chuvoso. Tal ordenamento deve ser observado com rigor - e exatidão (CUXY e HERBETTA, 2016).

Nessa direção o campo da etnomusicologia corrobora o exposto. Para Menezes Bastos (2007), a música indígena pode ser vista a partir de alguns princípios. Seu caráter tradutor, ou seja, como centro integrador dos discursos míticos, epistêmicos e corporal. Seu caráter sequencial, ou seja, como uma estrutura que contempla diversas canções e eventos musicais compreendendo e codificando metassignificados e sentidos específicos. Seu caráter estético, ou seja, como se estrutura a partir de formações músico-coreográficas particulares.

As pesquisas realizadas por professores e professoras indígenas do NTFSI indicam o exposto e avançam nas possibilidades de entendimento das diversas musicalidades. Cunry, professor krahô da Escola Indígena 19 de Abril, da aldeia Manoel Alves Pequeno, trabalha em suas aulas com práticas pedagógicas musicais. Para ele, a música, ou me increr,

é muito importante na comunidade porque com ela se faz festa. A música faz parte de todos os momentos krahô: na caçada, na roça, entre os partidos, de madrugada, ao amanhecer... Por isso os Krahô ensinam as músicas para as gerações mais novas. A música serve para animar. A música fala sobre os saberes da natureza, dos pássaros, dos animais. Mostra a forma de comportamento dos animais e da natureza. Mostra a marcação do tempo e do espaço na aldeia - cada música tem uma hora certa (Entrevista em janeiro de 2015). 
Para Tupen, professor krahô da mesma escola,

as músicas que podem ser ensinados na sala de aula é de acordo com a idade dos alunos. A música é livre, as crianças escolhem as músicas que eles querem aprender... nós, professores, dentro da sala de aula trabalhamos com as músicas de acordo com o nível das crianças, nas séries atendidas, por exemplo: para as crianças do $1^{\circ}$ ao $5^{\circ}$ ano do ensino regular, trabalhamos somente com as músicas bem curtinhas, igual corinhos, onde eles aprendem a cantar com facilidade... são essas, da borboleta, macaco da mão gordo, guariba da orelha redondo, queixo inchado, peixe grande e sapinho (Entrevista em janeiro de 2015).

A atividade em referência teve como base a música abaixo, dentre outras do mesmo repertório, que foi apresentada por um ancião, copiada pelos alunos, praticada ao longo da semana e apresentada para comunidade fora da sala de aula na sexta-feira, dia de conclusão do projeto.

tepe ti japê tepe $t i$

tepe ti japê wa apu xà ne cô ca ampu mã ipar ri pê mã

craw kra a re xà ne cô ca ampu procurando se um grande peixe estou a procura de um grande peixe olhando para a água ouvindo um filhote de soco olhando para o cô

Entre os Krahô há outras tantas práticas pedagógicas relacionadas à música. A pesquisa de Gregório Huhte Krahô (2014) da aldeia Cachoeira também trata da musicalidade. Para ele, ao estudar a música nativa, os alunos têm contato com outros domínios culturais e saberes, como a história, a geografia, o território e até mesmo a matemática, apontando para o caráter transdisciplinar da música krahô. Para Huhte (2014), "desde sempre, o mundo Krahô tem a ver com a relação entre a esquematização de dominar músicas e o estudo de matemática local" (apud PIIKEN et al, 2016, p. 39). Sua pesquisa aponta para a importância da noção de exatidão - presente na música - para o modo de ser krahô.

Huhte diz que "as músicas são da natureza... e devem ser cantadas de maneira exata para a sustentabilidade... Aprendemos a cantar pelos pássaros, árvores, rio, céu e outras espécies, não tem música inventada. Sempre é o mesmo ritmo de cantar, dançar, pular", 
apontando para uma noção de permanência, presente no fato de que as músicas que são cantadas hoje são, neste sentido, as mesmas apreendidas dos animais e da natureza. As músicas não podem ser mudadas. A prática rigorosa de tal musicalidade garante a existência do grupo.

A música vem igualmente sendo foco de alguns outros projetos entre os Krahô. Professores da Escola Indígena 19 de Abril, da aldeia Manoel Alves Pequeno, criaram na matriz curricular da escola um tema baseado na prática da música tradicional. Conforme Cunry,

expressar essa manifestação nos aproxima de nosso
sentimento étnico e transforma tudo em alegria. Com a
música a escola fica mais alegre. Através dos temas
contextuais os alunos da Escola 19 de Abril irão
conhecer, valorizar, e pesquisar sua própria cultura
(Entrevista em janeiro de 2015).

Além da alteração na matriz curricular, segundo Aldé (2013), os Krahô, os Krahô têm participado de projetos que tratam do uso de tecnologia e que tem a música como base,

como o Projeto Ponto de Cultura Casa da Memória Viva Krahô (Kapey3/UFG/Minc); Projeto Rádio Hartãt em parceria com a Faculdade de Comunicação e Biblioteconomia (FACOMB) da UFG; e o Projeto Banco Sonoro Inkre' $r$ : registros do universo musical Krahô (ITS/PUC Goiás) (ALDÉ, 2013, p. 15).

Entre os Apinajé, a situação de uso da música enquanto prática pedagógica é similar. A pesquisa de Julio Kamêr Apinajé (2013), professor da Escola Estadual Indígena Tekator, na aldeia Mariazinha, por exemplo, tem como centro a ideia de que, para se proteger o território apinajé das queimadas e, assim, manter seus recursos naturais protegidos e garantir sua sustentabilidade, é preciso cantar as músicas tradicionais. Neste contexto, algumas músicas têm relação especial com lugares do território, os quais possuem recursos específicos, como o babaçu, que são constituintes do que se pode chamar de cultura, pois geram objetos específicos, recursos alimentares, promovem organização social particular e, entre outras coisas, possuem história e música. 
A partir daí, Kamer cria práticas pedagógicas intra e interculturais relacionadas ao tema, e aponta para sua importância na matriz curricular nativa. Segundo Kamer, portanto, a música tradicional traz em si um conjunto de saberes, relações e intervenções fundamentais para a sustentabilidade do território, garantindo a existência do grupo e apontando para a interessante relação entre uma percepção de cultura e a prática dos cantos ditos tradicionais. Esta música não pode ser vista, portanto, de forma isolada. Ela é intrinsecamente conectada a outros aspectos do universo apinajé, de modo que cantar determinadas canções indica o cuidado com lugares do território, assim como garante a sustentabilidade da população.

O trabalho de conclusão de curso de Kamer no NTFSI é intitulado "Xahtã mẽ pahte amnhĩ nhĩpêx ho hihtỳx (Sustentabilidade): relações entre queimadas e cantorias no território Apinajé". Neste trabalho, Júlio busca, a princípio, definir em termos apinajé o que é sustentabilidade (xahtã mẽ pahte amnhĩ nhĩpêx ho hihtỳx). Segundo ele, o conceito indica as relaçãoes intrínsecas entre território, recursos naturais, objetos, organização social, língua materna e música. Para os Apinajé, a prática de seus cantos estabelece formas particulares de se relacionar com as pessoas e com a natureza, indicando que a percepção de cultura em tela tem a ver com relações particulares com agentes diversos, dos seres humanos ao que se chama natureza.

O tema da música se tornou central, inclusive, para a escola Tekator, onde leciona Kamer. Lá, há em andamento um projeto intitulado Grernhõxwynh Nywjê - Fortalecimento da Cantoria entre os Jovens nos Rituais Apinajé, cujo objetivo é a formação de cantores e cantoras. Segundo Kamer, "junto e em parceria com a escola [a ideia] é incentivar e envolver os jovens no aprendizado de nossos conhecimentos tradicionais e a cultura (Panhĩ) Apinajé". Para o professor, como se pode ver, a música é uma espécie de matriz de saberes, estando relacionada com os conhecimentos indígenas.

Kamer afirma, ainda, que a música pode transformar a escola indígena. Segundo ele, "essa iniciativa da Escola e da comunidade tem a finalidade de organizar e fortalecer nossa participação no sentido de construir e efetivar uma Educação Escolar Indígena própria segundo nossa concepção de cultura" (KAMER, 2016, n.p.), apontando para 
sentidos particulares de cultura (HERBETTA, 2016). O projeto em tela segue também parâmetros definidos anteriormente e presente em outras práticas pedagógicas. Antes dele, anciãos já participavam das aulas transmitindo seus "conhecimentos e sabedorias".

A música aparece também em projetos de pesquisa e práticas pedagógicas krikati. Jair Krikati, morador e professor da aldeia São José/MA, conta que sua avó, antigamente, já se preocupava com a diminuição da prática musical entre as crianças krikati. Segundo outro professor krikati, há alguns objetos que não estão sendo mais produzidos, o que acaba comprometendo a organização de alguns rituais. A pesquisa em referência busca mobilizar parte da população através da escola - para a produção destes objetos de modo a reativar alguns momentos importantes para a comunidade. Neste sentido, cada um destes objetos especiais possui também sua música, apontando para a relação já comentada de associação entre música e outros domínios. Não sendo possível, portanto, produzir tais objetos sem o conhecimento musical. Assim, lá, se se deixa de cantar a música o objeto perde seu sentido no rito.

Além dos projetos citados, muitos dos projetos políticopedagógicos (PPPs) produzidos no curso de especialização do NTFSI também têm a música como centro. O NTFSI iniciou em 2014 sua segunda turma do curso de especialização Educação Intercultural $e$ Transdisciplinar: gestão pedagógica. A experiência da primeira turma da especialização foi bastante rica e apontou desafios para professores indígenas e não indígenas, os quais são centrais para se pensar a questão da educação escolar indígena no Brasil. Note-se que o objetivo do referido curso é o de colaborar na produção do PPP de cada escola indígena participante. E que cada PPP deve preferencialmente possuir uma nova matriz curricular.

O PPP Gavião (2014) da Escola Indigena Crỹ'tohmre Cahohwpor da aldeia Governador, por exemplo, traz em seu texto uma lista com músicas transcritas das festas tradicionais. Como o PPP postula,

as festas Gavião são musicais. Cada ritual desses é composto por um conjunto de músicas que pertencem somente àquela festa. Mas, vale ressaltar que, em todos esses rituais, são cantadas as músicas de pátio, conhecidas entre os Pyhcop Cati como me ẽhncre 
caprẽh (músicas lentas) e me ẽhncre pajpax (músicas animadas). No entanto, existem algumas músicas muito animadas que são conhecidas entre os Pyhcop Cati como me hỳhcr.hn (PPP GAVIÃO, 2014, p. 15).

Diz-se ali que é a partir do estudo desta musicalidade que o aluno poderá conhecer de forma mais adequada temas, percepções e categorias dos saberes gavião. É através das músicas gavião que espera-se obter a formação adequada do sujeito. Conforme o PPP, é preciso fortalecer a

participação de jovens e crianças na organização desses eventos, já que atualmente temos apenas nove (9) cantores nas aldeias da T.I Governador. Assim, é importante envolver as crianças e jovens nas festas tradicionais, de forma que elas sejam ensinadas pelos cantores no pátio e na escola. As crianças e os jovens participando fora da escola junto com os organizadores de festa, aprenderão sobre os cânticos (os que são cantados pela manhã, a tarde, a noite e de madrugada), cânticos das festas, as pinturas usada nas festas, uso de matéria-prima que são usados nos adornos. Aprendendo a organização de subgrupos, que tipo de cântico (musica) aquele subgrupo canta, e se e para se pintar (PPP GAVIÃO, 2014, p. 12).

Como se pode perceber, para os Gavião, o aprendizado da musicalidade indígena tem a ver com o próprio conhecimento de mundo da população. Ela, música, tem a ver com as pinturas, festas, organização social e com algumas categorias importantes para a formação do sujeito. Nesta direção, há uma proposição de que a matriz curricular da escola gavião seja uma matriz bastante musical.

Note-se que a pesquisa sobre as musicalidades e sua aplicação na escola, apontando para uma pedagogia musical, não se restringem aos inúmeros grupos timbira. Outras tantas pesquisas presentes no NTFSI que se transformam em práticas pedagógicas centram-se no tema da música. Para os Javaé, por exemplo, a comunidade decidiu

por unanimidade que o professor Marco Kalari trabalhasse com as músicas, pois elas estão se perdendo e que os homens mais velhos iriam ajudá-los por ser uma arte que eles dominam melhor e que não querem que se percam (KALARI, 2014, p. 7). 
Segundo Kalari,

até então, a minha preocupação, vem atrás do desaparecimento de diferentes tipos de músicas do povo Javaé, que tem a grande importância para o nosso povo, que na sua ausência, traz a tristeza, no âmbito da nossa comunidade indígena (KALARI, 2014, p. 7).

Para ele, os jovens, especialmente, estão praticando as músicas que vêm de fora da aldeia, mais especificamente, músicas não indígenas, que constituem espaços de lazer e não atuam como transmissoras de um conhecimento importante para a comunidade. A pesquisa do professor tem como objetivos

manter as músicas vivas, na memória do povo Javaé, com a ajuda de arquivos e da tecnologia, em forma de escrita e oral para manter a alegria e a felicidade na realidade da comunidade. Separar o ritmo das músicas, que são usadas por dois Irasò/aruanãs, Weru e Ijareheni e dos espíritos, que nós acreditamos nos nossos rituais; conhecer a história do surgimento das músicas do povo Javaé para que seja conhecido, futuramente em novas gerações; observar a situação de como está, o processo de perda das músicas do povo Javaé, na comunidade; resgatar as músicas que já se perderam há tempos no mundo dos adolescentes para que sejam fortalecidos nas futuras gerações que estão vindo, adiante dos crescimentos de populações indígenas (KALARI, 2014, p. 8).

As músicas javaé, portanto, apontam para modos de ser dos sujeitos, a partir da prática de ritmos específicos, e indicam também constituir uma matriz de saberes que é colocada em oposição às músicas ocidentais. Dessa forma, deixar de lado esta musicalidade em detrimento de outras é desvalorizar, segundo professores javaé, a identidade indígena.

A musicalidade é igualmente central para o estabelecimento de novas práticas pedagógicas em outros espaços do país, para além do NTFSI. Para os Pataxó-Hãhãhãe, por exemplo,

desenvolvemos na prática pedagógica, várias atividades interessantes. Entrevistamos pessoas da comunidade, 
assistimos filmes referentes à cultura indígena, realizamos nosso ritual do Toré e para isso, fizemos pintura corporal, dançamos juntos e transformamos a sala de aula em um espaço cultural mesmo (GERLIC, 2012, p. 32).

O toré, rito musical, é, assim, apropriado nas disciplinas de português, de matemática, de história e ciências, permitindo a esta escola atuar com base em uma matriz cultural.

Para o professor hãhãhãe,

também recebemos visitas dos anciões na sala de aula, para conversar sobre o resgate do nosso idioma. Essas atividades foram desenvolvidas objetivando melhorar a cada dia a minha prática pedagógica, ampliando cada vez mais os conhecimentos culturais da comunidade e dos meus alunos (GERLIC, 2012, p. 32).

Conforme o intelectual indígena, "com o tema 'Preservação da Cultura', pretendo esclarecer a importância da sabedoria dos ancestrais usando a conscientização da cultura para nossa comunidade" (GERLIC, 2012, p. 32).

\section{Pedagogias musicais e decoloniais: A música em si!}

Como se pode perceber, a música constitui domínio privilegiado para os professores e professoras indígenas do NTFSI - e alhures. Percebe-se claramente que é muitas vezes a partir dela - música - que os professores pensam e produzem suas práticas pedagógicas, apontando para uma pedagogia particular. Nestas práticas, como se pode notar, a música não é apenas um recurso pedagógico, um instrumento que auxilia a compreensão de algum outro conteúdo. Ela é importante em si, o que se dá a partir de uma série de princípios.

Em primeiro lugar, pode-se destacar que o uso da música em sala de aula tem como função acessar a memória coletiva do grupo. Desta forma, ela pode (re) estabelecer relações inter geracionais entre os anciãos e os jovens, já que os mais antigos são os conhecedores da teoria musical nativa e são eles que são chamados a participar destas aulas e projetos. Os anciãos são efetivamente (re) valorizados no 
contexto destas experiências. O caso do uso do toré na escola hãhãhãe é evidente sobre isto. O caso do projeto musical apinajé também corrobora a questão.

Nesta direção, estas musicalidades parecem registrar ou codificar um conjunto de saberes e informações que apontam para a relação de cada população com o mundo. Nestes cantos há personagens marcantes, histórias relevantes, lugares especiais, práticas e condutas adequadas, assim como percepções do universo. Entre os Gavião, como visto, os cantos apontam para, entre outras coisas, o complexo sistema de organização social baseada em metades e partidos. Sendo assim, a escola indígena deve-se atentar para o fato de que os alunos e alunas devem aprender a cantar o repertório tradicional dos cantos para a compreensão deste universo particular. Note-se que forma e conteúdo não podem ser dissociados, a música constituindo uma matriz de saberes.

Neste sentido, segundo Aldé, em relação aos Krahô,

os cantos também aproximam as novas gerações dos conhecimentos acerca de toda a biodiversidade do Bioma. Das cinco traduções realizadas dos Cânticos do Pohy Jô Crow (Ritual da Tora de Milho) e duas Cantigas de Maracá, mais de vinte espécies animais e vegetais vieram a tona, encantando-nos. Repletas de detalhes e poesia, as letras dos cantos Krahô revelaram de maneira singular a biodiversidade da fauna e da flora nativa de um dos mais antigos e complexos Biomas do planeta. O acervo musical Krahô representa uma verdadeira Enciclopédia Sonora do Cerrado. Um patrimônio imaterial de extrema importância para a humanidade (ALDÉ, 2013, p. 55).

Em seguida deve-se notar, especialmente, que a prática pedagógica musical traz implícitas noções particulares de cada epistemologia indígena. Neste cenário, para Borges, "entre os timbiras e, em particular, entre os mehi, o ouvir recebe ênfase social enquanto faculdade moral e cognitiva associada ao conhecer-compreender" (BORGES, 2015, p. 15).

Neste sentido, a ideia de ordem ou exatidão, por exemplo, contida nas músicas krahô são fundamentais para a formação da pessoa lá. Já entre os Javaé, as músicas parecem apresentar um ritmo que faz 
parte de outros domínios da existência.

Desta forma, conhecer e praticar tais musicalidades é concomitantemente passar por um processo de formação que tem como base os saberes particulares de cada população - estes baseados em noções como ordem, ritmo, beleza, entre outras. Aldé observa algo similar entre os Krahô. Para ela,

existe um equilíbrio entre uso e reposição, entre trabalho e descanso, um ritmo. Apesar de sua persistência, o Pica pau como ser vivo, precisa recarregar suas energias; assim como a roça depois da colheita precisa de uma pausa; assim como a cigarra precisa cantar depois da seca pra chamar a chuva; e as sementes do fogo pra quebrar a dormência. Sucessões, ciclos, reguladores de um movimento coletivo e integrado (ALDÉ, 2013, p. 28).

A música Krahô também é baseada nestes ritmos e seqüências específicas.

Pode-se dizer, ademais, que tais práticas pedagógicas musicais desvelam um aspecto central do pensamento indígena, qual seja, seu caráter associativo e não fragmentário. Assim, nestas práticas, a musicalidade em referência, como comentado, está conectada com uma série de outros domínios, estabelecendo armações particulares e fundantes do socius de cada grupo, indicando um caráter transdisciplinar. A prática pedagógica elaborada pelo professor Julio Kamer Apinajé, por exemplo, desvela uma armação na qual determinado repertório musical está conectado intrinsecamente a lugares do território, a determinados recursos naturais e a práticas específicas, de modo que a prática musical em tela garante a sustentabilidade do grupo e combate a queimada, problema grave enfrentado pelos Apinajé.

Esta característica associativa presente na música parece apontar, ainda, para a noção de esticar, presente em muitas pesquisas realizadas pelos professores e professoras indígenas no NTFSI. Segundo estas pesquisas, esticar tem a ver com o que chamamos de contextualização, e nesta direção aponta para uma dinâmica relacional que conecta temas e domínios específicos, evidenciando a importância da relação em detrimento da fragmentação, e fundamentando um outro regime de conhecimento (HERBETTA, 2013). 
Por fim, pode-se notar uma dinâmica interessante presente nestas práticas pedagógicas musicais acerca da noção de transformação. Neste campo pode-se dizer que, por um lado, tais músicas, segundo os interlocutores indígenas, são as mesmas criadas pelos animais e pela natureza e transmitidas para alguns personagens fundadores de cada universo cultural, como já mencionado.

Neste sentido, para Pechincha,

afirmam também os krahô que seus repertórios de cantos são os mesmos desde que, em um tempo antigo em que os bichos e plantas "também eram gente", os aprenderam desses seres. Daí a necessidade que sentem de guardar o conhecimento desses repertórios tal como foram ouvidos da primeira vez, o que exige disciplina e técnicas de memória a serem observadas por aqueles que desejam ser cantadores (PECHINCHA, no prelo, p. 1).

Por outro lado, a retomada destas práticas musicais que se dá na escola parace indicar uma profunda transformação na educação escolar destas populações, já que voltam a produzir subjetividades baseadas em sua epistemologias particulares, em detrimento de uma escola colonizadora, baseada em uma matriz epistêmica eurocêntrica como sempre tiveram acesso. Neste contexto, para Grupioni,

\begin{abstract}
como um movimento pendular pode-se dizer que a escola se moveu num longo percurso do passado aos dias de hoje de algo que foi imposto aos indios a uma demanda que é atualmente por eles reivindicada. Utilizada no passado para aniquilar culturalmente estes povos, hoje tem sido vista com um instrumento que pode lhes trazer de volta 0 sentimento de pertencimento étnico, resgatando valores, práticas e histórias esmaecidas pelo tempo e pela imposição de outros padrões socioculturais (GRUPIONI, 2006, p. 44).
\end{abstract}

Neste sentido, estas populações estariam em um momento delicado da existência, já que graças ao violento processo de contato interétnico e ao descuido com ritmos e cuidados - e com a diminuição da prática musical -, muitos aspectos do jeito de ser de cada povo estariam adormecidos, como afirma o PPP da Escola Estadual Indígena Matyk (2016, no prelo). A música, neste sentido, segundo os 
professores apinajé, movimenta o universo e promove transformações. Do ponto de vista deles, o movimento é essencial à vida. Para Creuza Prumquoi Krahô, por exemplo, a vida tem a ver com o ritmo do maracá. A música é, portanto, transformação.

Nesta direção, nas palavras de Shepherd (1991), a música pode alterar o "status quo" social, constituindo um meio de expressão e comunicação que liga diretamente o sujeito ao grupo social e à sociedade inclusiva. Se a música ocidental permite ao sujeito sentir a sua ocidentalidade, tanto quanto conhecê-la, então a música indígena permite ao índio sentir sua indianidade, tanto quanto compreendê-la.

Uma matriz curricular mais musical, neste cenário, pode fazer com que tais comunidades passem a revalorizar e praticar aspectos centrais de seus universos, indo de encontro à escola convencional.

Conclui-se, por fim, que a música nas novas matrizes curriculares das escolas timbira - e em outras escolas indígenas - é mais do que recurso pedagógico; trata-se de uma forma de ensino e aprendizagem. Uma pedagogia. Ela parece constituir, assim, uma dinâmica que, conforme Walsh, atua para:

\begin{abstract}
Recuperar, reconstruir y hacer re-vivir la memoria colectiva sobre territorio y derecho ancestral, haciendo esta recuperación, reconstrucción y revivencia parte de procesos pedagógicos colectivos, ha permitido consolidar comprensiones sobre la resistenciaexistencia ante el largo horizonte colonial y relacionarlas al momento actual. También ha contribuido a reestabelecer y fortalecer relacionarlas almomento actual. Tambien ha contribuido a reestablecer y fortalecer relaciones de aprendizaje intergeneracionales $y$, a su vez, emprender reflexiones sobre los caminos pedagógico-accionales por construir y recorrer (WALSH, 2013, p. 43).
\end{abstract}

Neste sentido, pode-se refletir sobre a hipótese de que a música no sistema de pensamento em tela é o operador central da teoria pedagógica destes professores e professoras, e que pedagogia para eles é formação e trans-formação.

Aventa-se, então, a hipótese de que, nestas escolas, um currículo sem base musical é o mesmo que um currículo colonizado. Dantas trata da noção de currículo colonizado (2015, p. 27). Para o autor, o currículo 
de filosofia da Secretaria de Educação do Paraná, por exemplo, é eurocentrado, pois ignora e distorce noções fundamentais de uma filosofia africana. Na mesma direção, ignorar o potencial da música enquanto modo de formação de pessoas é distorcer princípios fundantes dos regimes de conhecimento ameríndios - e outros.

Note-se, então, que tal reflexão deve ser importante para o fomento de políticas públicas adequadas à escola indígena. A possibilidade de cada escola indígena usar os modos particulares de aprendizagem, conquista presente no artigo 210 da Constituição federal de 1988, abre a possibilidade de se criarem modelos inovadores de educação. No caso aqui tratado, tais conquistas têm relação com uma nova percepção de música - ou melhor, de educação musical. Esta, em acordo com a discussão contemporânea acerca do tema em tela, aponta para a necessidade premente de uma centralidade na educação musical, a qual deve ter como características a transdicisplinaridade e a particularidade de cada cultura.

Pode-se pensar inclusive sobre a constituição de matrizes curriculares musicais.

Abre-se, assim, a possibilidade de uma educação contextualizada (FREIRE, 1983), a qual reforça a autonomia do sujeito e promove a formação de subjetividades descolonizadas (FANON, 1967).

Se a música em si parece não mudar, ela promove a dinâmica de transformação que tem impactos na formação do sujeito, da escola, da comunidade, do mundo. A música muda... "A música também tem que mudar... tem que mudar... e a música também tem que mudar..." (SCIENCE, 2009).

\section{Referências bibliográficas}

ALDÈ, Veronica. Sustentando o Cerrado na Respiração do Maracá: conversas com os Mestres Krahô. 2013. 75 f. Dissertação (Mestrado em Desenvolvimento Sustentável) - Universidade de Brasília. Brasília, [2013].

ALGAYER, Karine Regina; TRUGILlO Edneuza Alves. Música como ferramenta pedagógica no aprendizado da criança. Eventos Pedagógicos, Sinop, v. 4, n. 2, p. 136145, 2013. 
BORGES, Júlio César. Peixes, Lontras e Arraias: resistência étnica dos índios Krahô através da festa. Anthropológicas, Recife, v. 26, n. 1, p. 15-44, 2015.

CHERVEL, André. História das disciplinas escolares: reflexões sobre um campo de pesquisas. Teoria e Educação, Porto Alegre, n. 2, p. 177-229, 1990.

CORREIA, Marcos Antonio. A função didático-pedagógica da linguagem musical. Educar, Curitiba, n. 36, p. 127-145, 2010.

CUXY, Joel; HERBETTA, Alexandre. A imagética Mehi: reflexões iniciais sobre ritmos e imagens cupe e Krahô. Goiânia: Editora da UFG, 2016.

DANTAS, Luis Thiago Freire. Descolonização curricular: a Filosofia Africana no ensino médio. São Paulo: Editora PerSe, 2015.

FIGUEIREDO, Sérgio Luiz Ferreira de. A preparação musical de professores generalistas no Brasil. Revista da ABEM, Porto Alegre, v. 11, p. 55-61, 2004.

FANON, Frantz. Black Skin, White Masks. Nueva York: Grove Press, 1967.

FONTERRADA, Marisa Trench. De tramas e fios: um ensaio sobre música e educação. São Paulo/Rio de Janeiro: UNESP/Funarte, 2008. (Coleção Arte e Educação).

$\begin{aligned} & \text { Educação musical: propostas } \\ & \text { musical. }\end{aligned} \quad \begin{array}{cc}\text { criativas. In: Fundamentos da educação } \\ \text { hisponível }\end{array}$
$\begin{aligned} & \text { http://www.amusicanaescola.com.br/pdf/Marisa_Foterrada.pdf . Acesso em: } 11 \text { abr. } \\ & 2016 .\end{aligned}$

GRUPIONI, Luís D. B. Contextualizando o campo da formação de professores indígenas no Brasil. In: __ (Org.). Formação de professores indígenas: repensando trajetórias. Brasília: MEC, 2006. p. 39-68.

FREIRE, Paulo. Pedagogia do Oprimido. Rio de Janeiro: Paz e Terra, 1983.

GERLIC, Sebastián (Org.). Cantando as culturas indígenas. Ilhéus: Thydêwá, 2012.

HERBETTA, Alexandre Ferraz. Legislação e mito na educação escolar Timbira: o esticar e a pedagogia indígena no Brasil Central. In: SILVA, Maria do Socorro Pimentel da; BORGES, Mônica Veloso (Org.). Educação intercultural: experiências e desafios políticos pedagógicos. Goiânia: Editora da UFG, 2013.

A dinâmica dos temas contextuais e as transformações da educação escolar indígena. In: CASALI, Alípio; CASTILHO, Suely (Org.). Diversidade na educação: implicações curriculares. São Paulo: Editora da PUC/SP, 2016.

HUHTE Krahô, Gregorio. Formas exatas de ser Krahô: a relação entre a música e a matemática. Palestra apresentada ao NTFSI/UFG, 2014. 
KAMER Apinajé, Julio. Sustentabilidade: entre cantos e queimadas no território Apinajé. 2013. 49 f. Monografia (Graduação em Licenciatura Intercultural) Universidade Federal de Goiás, [2013].

Grernhõxỳnh nywjê: fortalecimento da cantoria entre os jovens nos rituais apinajé. 2016. Disponível em: http://uniaodasaldeiasapinaje.blogspot.com.br/2016/03/grernhoxynh-nywjefortalecimento-da.html . Acesso em: 14 jun. 2016.

KALARI Javaé, Marco. 2014. A origem das músicas do povo Iny Javaé. 2014. 47 f. Monografia (Graduação em Licenciatura Intercultural) - Universidade Federal de Goiás, [2014].

LANDER, Edgardo (Org.). Colonialidade do saber: eurocentrismo e ciências sociais perspectivas latino-americanas. Buenos Aires, Clacso, 2005. p. 55-70.

MENDES Rocha, Leandro; PIMENTEL DA SILVA, Maria do Socorro; BORGES, Mônica Veloso (Org.). Cidadania, interculturalidade e formação de docentes indígenas. Goiânia: Ed. da PUC-GO, 2010.

MENEZES BASTOS, Rafael José de. Música nas Sociedades Indígenas das Terras Baixas da América do Sul: Estado da Arte. Mana, Rio de Janeiro, v. 13, n. 2, p. 293 316, 2007.

Esboço de uma Teoria da Música: para além de uma Antropologia sem Música e de uma Musicologia sem Homem. Aceno, Cuiabá, v. 1, n. 1, p. 49-101, 2014.

MORAES, Jota J. O que é música. São Paulo: Brasiliense, 1983.

PIIKEN, Dodanin et al (Org.). Më pahte amji ton xà në ry ipinkrên nare, kôt cu pahtyj me to ihtyj: subsídios à prática pedagógica musical e decolonial a partir de experiências escolares Timbira. Goiânia: Editora da UFG, 2016.

PPP Apinajé da Escola Matyk da aldeia São José. Requisito para a conclusão do curso de Especialização em Educação Intercultural e Transdisciplinar: gestão pedagógica. Núcleo Takinahaky de Formação Superior Indígena. UFG - Universidade Federal de Goiás. No prelo.

PPP Gavião da Escola Indigena Crỹy'tohmre Cahohwpor da aldeia Governador. Requisito para a conclusão do curso de Especialização em Educação Intercultural e Transdisciplinar: gestão pedagógica. Núcleo Takinahaky de Formação Superior Indígena. UFG - Universidade Federal de Goiás. 2014.

PECHINCHA, Monica. Performance e educação indígena: notas sobre os cantos krahô (e sua entrada na escola). No prelo.

RENNER, Kátia. Onde está o significado da música? In: BEYER, Esther; KEBACH, 
Patrícia (Org.). Pedagogia da música: experiências de apreciação musical. Porto Alegre: Mediação, 2009.

RIZZON, Flavia G. A música e suas significações. In: BEYER, Esther; KEBACH, Patrícia (Org.). Pedagogia da música: experiências de apreciação musical. Porto Alegre: Mediação, 2009. p. 51-68.

SCIENCE, Chico. Mosaicos: a Arte de Chico Science. TV Cultura. 2014. Disponível em: https://www.youtube.com/watch?v=Flg4AccZ54A . Acesso em: 11 abr. 2014.

SHEPHERD, John. Music as Social Text. Cambridge: USA, 1991.

SUBTIL, Maria José Dozza. A lei n. 5.692/71 e a obrigatoriedade da educação artística nas escolas: passados quarenta anos, prestando contas ao presente. Rev. bras. hist. educ., Campinas, v. 12, n. 3, p. 125-151, 2012.

WALSH, Catherine. Pedagogia decoloniales: practicas insurgentes de resistir, (re)existir y (re)vivir. Quito:.Abya Yala, 2013.

WISNIK, José Miguel. O som e o sentido: uma outra história das músicas. São Paulo: Companhia das Letras, 1989.

Recebido em: 09/05/2016 * Aprovado em: 23/05/2016 * Publicado em: 30/06/2016 